\title{
Mineração
}

\section{Célula de carga de impacto na caracterização de materiais para a cominuição. Parte 1: Calibração}

\author{
Luís Marcelo M. Tavares \\ Laboratório de Tecnologia Mineral, Programa de Engenharia Metalúrgica e de Materiais, COPPE/UFRJ \\ E-mail:tavares@ufrj.br \\ Alfredo da Silva Lima \\ Laboratório de Tecnologia Mineral, Programa de Engenharia Metalúrgica e de Materiais, COPPE/UFRJ \\ E-mail:lima@metalmat.ufr..br
}

\begin{abstract}
Resumo
Nas últimas décadas, tem crescido, de forma significativa, a utilização de informações fundamentais de fratura de partículas, na modelagem e simulação de processos de cominuição, na indústria. Entre os equipamentos utilizados, na avaliação do comportamento mecânico de partículas, se destaca a célula de carga de impacto. Ela é um híbrido entre o aparelho de queda de peso e a barra dividida de Hopkinson e permite a medida da curva forçadeformação resultante do impacto de partículas individuais ou de leitos de partículas sob condições de carregamento rápido. Células de carga de impacto com diferentes diâmetros foram projetadas e construídas na COPPE/ UFRJ, permitindo a caracterização da fratura de partículas dentro de um intervalo amplo de tamanhos e energias aplicadas. Essa primeira parte do artigo descreve o funcionamento do aparelho e a sua calibração, realizada a partir de princípios da propagação de ondas longitudinais em barras e da teoria de contatos de Hertz.
\end{abstract}

Palavras-chave: impacto, fratura de partículas, cominuição.

\begin{abstract}
In recent decades there has been a major growth in the application of fundamental particle fracture data to modeling and simulation of industrial comminution processes. Among the devices used in assessing the mechanical response of particles is the impact load cell. It is a hybrid between the drop weight apparatus and the split Hopkinson pressure bar, which allows measurement of the force-deformation response from the impact of single particles and particle beds. Impact load cells with different diameters have been designed and installed at COPPE/UFRJ, so that it is now possible to measure fracture characteristics of particles within a wide range of sizes and input energies. This first part of the paper describes the operation and calibration of the device, carried out from principles of the longitudinal wave propagation theory and the Hertz theory of contacts.
\end{abstract}

Keywords: impact, particle fracture, comminution. 


\section{Introdução}

Durante a sua formação, engenheiros e técnicos envolvidos no tratamento de minérios são familiarizados com os ensaios tradicionais de caracterização de minérios para a cominuição. Exemplos desses ensaios são os propostos por Bond [1], usados no cálculo dos índices de trabalho (Wi) de moinhos de bolas, barras e de britagem, e o ensaio de Hardgrove, empregado na determinação do índice de moabilidade (HGI). Esses índices, junto às equações empíricas correspondentes, permitem a estimativa do consumo energético específico e/ou a capacidade unitária, úteis no dimensionamento de moinhos e britadores.

Ainda que permitam caracterizar, com um número prático e de fácil lembrança, a resposta esperada do material aos processos de britagem ou moagem, esses índices tradicionais de moabilidade e britabilidade possuem importantes limitações de ordem prática: além de serem essencialmente apenas aplicáveis aos equipamentos para os quais foram desenvolvidos, não sendo utilizáveis na descrição de novos equipamentos, esses índices são de pouca utilidade na otimização de equipamentos e circuitos de cominuição, pois são incapazes de caracterizar, com suficiente detalhe, os microprocessos existentes na cominuição. Além disso, uma vez que esses índices não caracterizam propriedades fundamentais dos materiais e, sim, o seu comportamento, quando cominuído, em um dado equipamento, sob condições padronizadas, a sua avaliação depende, sobremaneira, da aderência estrita do operador ao procedimento padronizado.

Quando analisada no seu nível mais fundamental, a cominuição pode ser compreendida como o processo repetido de captura das partículas (seja por corpos moedores em rota de colisão no interior de um moinho ou por revestimentos de um britador, por exemplo) e de aplicação de cargas, que resulta na deformação, fratura primária e geração de fragmentos. Sob essa ótica, que coloca a deformação e a fratura da partícula em destaque, seria razoável esperar que resultados de medidas usuais do comportamento mecânico (módulo de elasticidade de Young, tensão de ruptura por compressão ou tração, tenacidade à fratura $\mathrm{K}_{\mathrm{IC}}$, etc.) de corpos-de-prova com formatos regulares fossem diretamente aplicáveis, na descrição da cominuição. Entretanto, na prática, observa-se que isso não é, geralmente, possível, tendo em vista que a maior parte dessas medidas usuais de comportamento mecânico tem encontrado, comparativamente, pouca correlação com o desempenho de minérios na cominuição [2]. De fato, Bearman et al. [2] demonstraram que, entre diversas medidas realizadas em corposde-prova de uma variedade de rochas, apenas a tenacidade à fratura apresentou uma boa correlação com o consumo energético na britagem. Uma das explicações para isso é a influência significativa da forma da partícula e do complexo estado de tensões envolvido no seu carregamento. Tendo isso em vista que a preparação de corpos-de-prova de rochas para os ensaios descritos é uma operação tediosa e dispendiosa, ensaios de fratura de partículas se tornaram uma importante alternativa, na análise fundamental da cominuição. Diversos equipamentos têm sido desenvolvidos, que permitem a análise da fratura e da fragmentação de partículas dos mais variados tamanhos e sob diferentes condições de carregamento, que vão, por exemplo, desde a fragmentação por abrasão de partículas com tamanhos menores que $100 \mu \mathrm{m}$ [3] até a compressão lenta de partículas com até $1 \mathrm{~m}$ [4]. Esses ensaios permitem avaliar, direta ou indiretamente, a resposta do material particulado à aplicação dos esforços.

Na maior parte dos equipamentos de cominuição industrial (moinhos diversos e britadores de mandíbulas, giratórios e cônicos, entre outros), o modo de carregamento predominante é a compressão, a velocidade de carregamento é moderada, tipicamente de um decímetro a, aproximadamente, uma dezena de metros por segundo [5]. Esse modo de carregamento, normalmente chamado de impacto duplo ou, apenas, impacto [6], pode ser convenientemente estudado com o auxílio de um aparelho desenvolvido a duas décadas na University of Utah por Reiner Weichert [7]. O aparelho, denominado célula de carga de impacto (Ultrafast Load Cell ou Impact Load Cell em inglês), permite a medida de forças e deformações sofridas por partículas individuais [8] e leitos de partículas [9] sujeitos a carregamentos a velocidades no intervalo de alguns decímetros a vários metros por segundo. A célula de carga de impacto (CCI) é hoje uma tecnologia madura, usada com sucesso em uma variedade de aplicações [6]. Informações obtidas na CCI são usadas na medida de uma série de grandezas de interesse, incluindo a tensão de ruptura, a rigidez, a energia específica de fratura da partícula [6] e a energia total absorvida pela partícula durante todo o evento de impacto [10]. Além disso, da mesma forma que qualquer outro aparelho de queda de peso (drop weight tester), a CCI também permite a coleta dos fragmentos para análise, a partir dos quais é possível estabelecer a relação entre a energia aplicada (ou utilizada) e a fragmentação ( $t_{10}$ versus energia de cominuição usada na simulação de britadores e moinhos [11]).

Células de carga de impacto têm sido construídas em alguns dos mais destacados centros mundiais de pesquisa em cominuição (Tabela 1). Com o intuito de promover um maior desenvolvimento dessa tecnologia, bem como a sua aplicação na indústria mineral brasileira, células de carga de diferentes diâmetros foram projetadas e construídas no Laboratório de Tecnologia Mineral da COPPE. Nessa primeira parte do artigo, os princípios da medida na CCI e o procedimento de calibração a partir da teoria de contatos de Hertz são descridos. Na segunda parte é analisada a aplicação da CCI na caracterização de um número de materiais de interesse.

\section{O aparelho 2.1 Descrição}

Um diagrama esquemático da CCI é apresentado na Figura 1. O ensaio inicia 
Luís Marcelo M. Tavares et al.

com o posicionamento de uma partícula, previamente pesada, no topo da barra de aço. A partir de uma altura conhecida e selecionada previamente, de modo a garantir que todas partículas contidas na amostra fraturem, uma bola de aço é solta, caindo sob a ação da gravidade em queda livre até se chocar contra a partícula. No instante em que a bola cruza o feixe de laser, a aquisição de dados é iniciada. O impacto, que causa a deformação e fratura da partícula, também é responsável pela propagação de uma onda compressiva no interior da barra de aço. A passagem dessa onda de compressão causa uma deformação muito
Tabela 1 - Diâmetros da barra de células de carga de impacto documentadas para ensaios de fratura de partículas.

\begin{tabular}{c|c|c}
\hline Instituição & $\begin{array}{c}\text { Diâmetros das } \\
\text { barras (mm) }\end{array}$ & Referência \\
\hline University of Utah (EUA) & 19,51 & Weichert e Herbst [7] \\
\hline CSIRO (Austrália) & $20,60,100$ & Frandrich et al. [12] \\
\hline JKMRC (Austrália) & 20,25 & $\begin{array}{c}\text { Briggs [13], Bourgeois e } \\
\text { Banini [14] }\end{array}$ \\
\hline COPPE-UFRJ (Brasil) & $9,19,63,100$ & Lopes [15], Pereira [16] \\
\hline
\end{tabular}

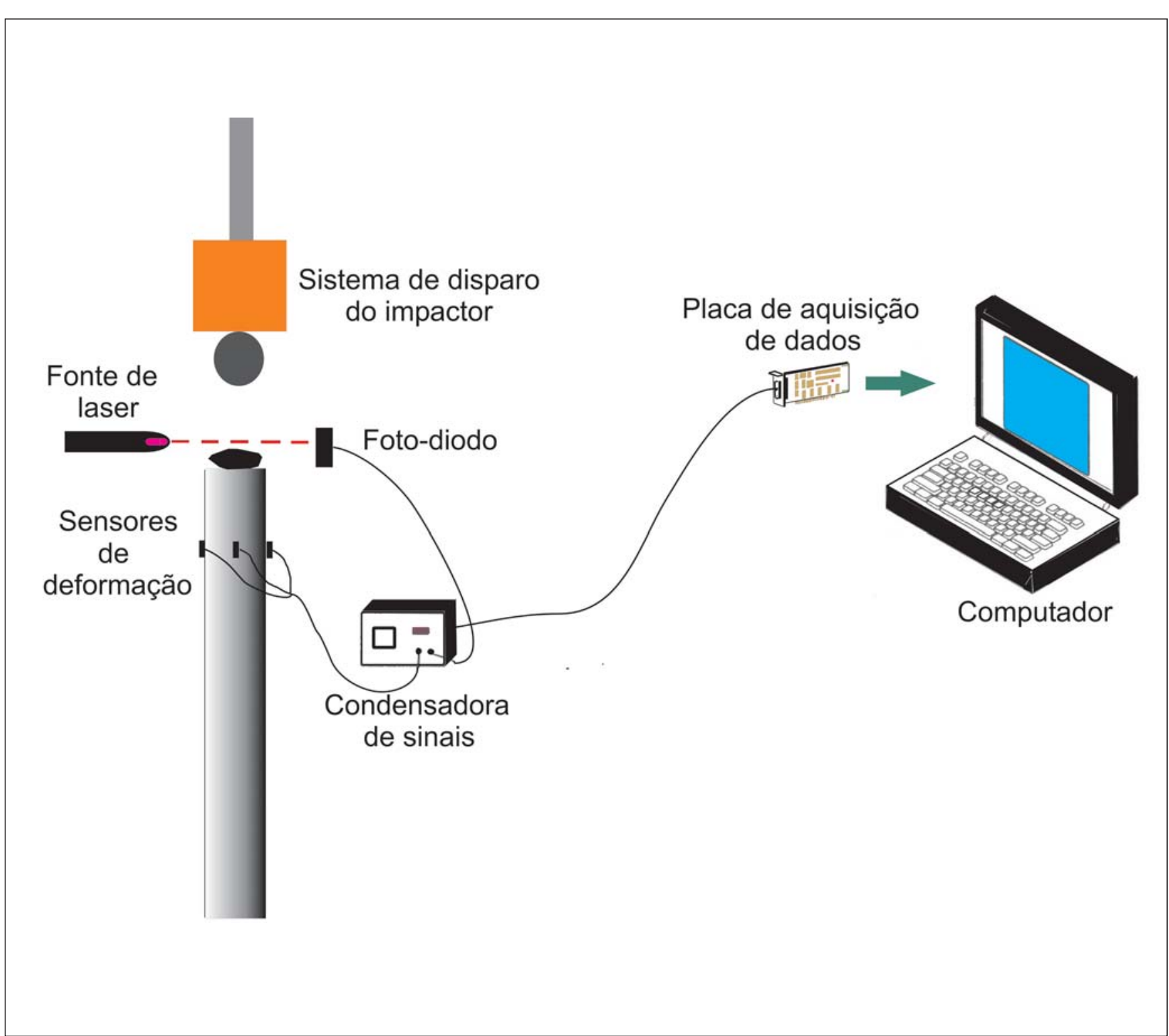

Figura 1- Diagrama esquemático da célula de carga de impacto. 
pequena, mas mensurável, nos sensores de deformação (strain gauges) de alta resolução, posicionados lateralmente na barra metálica (Figura 2). Essas deformações se transformam em alterações das resistências elétricas $\left(R_{1}, R_{2}, R_{3}\right.$ e $\left.R_{4}\right)$ dos strain gauges. Esse sinal é, em seguida, condicionado com o auxílio de uma condensadora de sinais que usa um circuito-ponte de Wheatstone (Figura 2) e transformado em microvoltagem, com armazenamento contínuo em um osciloscópio digital ou em um microcomputador (equipado com uma placa de aquisição de dados de alta resolução) para análises a posteriori. O aparelho é, ainda, equipado com uma caixa para a coleta dos fragmentos resultantes de cada ensaio, os quais são juntos àqueles de ensaios com outras partículas do mesmo lote para posterior análise granulométrica. Com isso, o aparelho ainda permite avaliar a influência da energia de impacto aplicada (ou da energia efetivamente absorvida pelas partículas) na fragmentação.

Com freqüência, indivíduos não familiarizados com o aparelho questionam sobre a possibilidade do uso de células de carga piezoelétricas (como aquelas usadas em balanças digitais modernas de laboratório), as quais são atualmente amplamente disponíveis, em substituição à barra da CCI instrumentada com strain gauges. Apesar da simplicidade dessa solução, ela é ineficaz para a investigação de um evento de impacto, pois as medidas obtidas seriam influenciadas pelas vibrações internas que ocorrem no interior do sensor piezoelétrico, mascarando os resultados. Uma alternativa válida aos strain gauges é o uso de acelerômetros piezoelétricos, posicionados na extremidade oposta da barra de impacto [17].

\subsection{Princípios das medidas}

A CCI permite o cálculo, tanto das forças, quanto das deformações que uma partícula sofre durante um impacto. A força exercida no topo da barra pela partícula, durante um impacto, é calculada a partir da lei de proporcionalidade dos sensores de deformação e da lei de Hooke. Considerando que não ocorre dispersão ou atenuação da onda do ponto de contato até a estação de medida (sensores) e que as deformações no interior da barra são predominantemente elásticas (o que é normalmente válido, considerando o baixo nível de tensões medidas), então a força é dada por

$F_{r}=A Y \varepsilon$

onde $A, Y$ e $\varepsilon$ são a seção transversal, o módulo de elasticidade e a deformação unitária da barra, respectivamente. A deformação unitária da barra, por sua vez, é relacionada à resposta do circuito-ponte (Figura 2) por

$\left(\frac{V_{\text {out }}}{V_{\text {in }}}\right)=G F \lambda \varepsilon$

na qual $\lambda$ é a constante de proporcionalidade do circuito-ponte, a qual depende da configuração do próprio circuito e deve ser ajustada a partir da calibração do aparelho, GF é o fator do sensor de deformação (fornecido pelo fabricante), $V_{\text {in }}$ é a tensão de excitação do circuitoponte e $V_{\text {out }}$ são as tensões medidas de saída durante o ensaio. Substituindo a Equação (2) em (1), tem-se a expressão para o cálculo da força exercida sobre a barra

$$
F_{r}=\frac{A Y}{G F \lambda}\left(\frac{V_{\text {out }}}{V_{\text {in }}}\right)
$$

Dessa forma, dadas as propriedades físicas e mecânicas da barra, as constantes de proporcionalidade do circuito-ponte e o fator do sensor de deformação, o sinal de voltagem, em função de tempo armazenado, para cada ensaio, pode ser individualmente transformado em um gráfico de força, em função de tempo.

A compressão que uma partícula posicionada no topo da barra sofre não é determinada diretamente. Ela é calculada a partir do balanço do momento da bola em queda livre, assim como da deformação da barra. O movimento de uma bola, durante o impacto, pode ser determinado a partir da equação de conservação de momento linear

$m_{b} \frac{d^{2} u_{b}}{d t^{2}}=-F_{b}+m_{b} g$

sendo $u_{b}$ a posição do centro de gravidade da bola, $m_{b}$, a sua massa, $F_{b}$, a força exercida pela partícula contra a bola e $g$ é a aceleração da gravidade. Integrando a Equação (4) sujeita às condições iniciais, no instante de contato $(t=0)$, dadas por $d u_{b} / d t=v_{o}$ e $F_{b}=0$, tem-se

$$
\frac{d u_{b}}{d t}=v_{o}+g t-\frac{1}{m_{b}} \int_{0}^{t} F_{b}(t) d t
$$

sendo $v_{o}$, a velocidade da bola no instante de contato, uma vez que, na maior parte dos casos, é possível garantir que

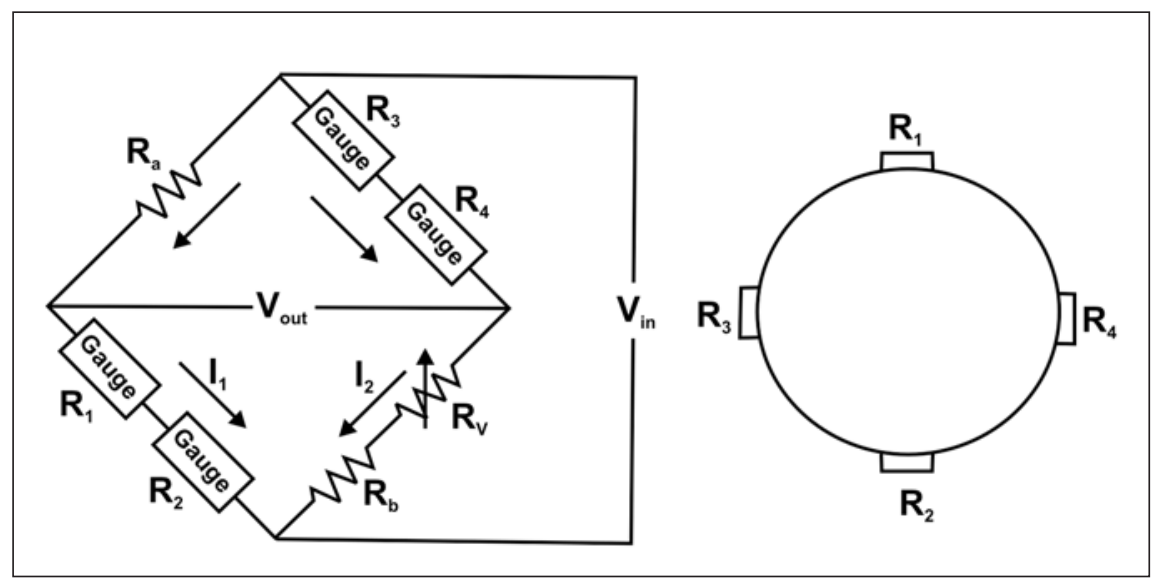

Figura 2 - Configuração do circuito de Wheatstone usado na condensadora de sinais $\left(R_{1}, R_{2}, R_{3}\right.$ e $R_{4}$ são as resistências dos strain gauges, $R_{a}$ e $R_{b}$ são resistências fixas e $R_{v}$ é a resistência variável), obtida com o uso de um potenciômetro. 
condições de queda livre predominem durante o ensaio, $v_{o}=(2 g h)^{1 / 2}$, na qual $h$ é a altura líquida de queda (distância inicial entre a base da bola e o topo da partícula). Durante o choque, diferentes tipos de ondas propagam no interior do sólido, que incluem as ondas longitudinais, as transversais e as de Rayleigh [18]. Tendo em vista o modo de contato e o grande comprimento da barra em relação ao diâmetro, é possível considerar apenas as ondas longitudinais no interior da barra de aço. Nesse caso, as forças e as deformações do topo da barra são relacionadas por [18]

$$
\frac{d u_{r}}{d t}=\frac{1}{\rho A C} F_{r}(t)
$$

sendo $C$ a velocidade de propagação da onda de deformação na barra. Considerando que as forças nas superfícies em contato se encontram em equilíbrio $\left(F_{r}=F_{b}=F\right)$, então subtraem-se as Equações (5) e (6), que, após integração dão:

$\alpha(t)=v_{o} t+\frac{g t^{2}}{2}-\frac{1}{m_{b}} \int_{0}^{t} \int_{0}^{\tau} F(\hat{\tau}) d \hat{\tau} d \tau-\frac{1}{\rho A C} \int_{0}^{t} F(\tau) d \tau$

sendo $\alpha=u_{b}-u_{r}$ e $\hat{\tau}$ é uma variável de integração.

A Equação (7) permite o cálculo da aproximação entre o centro de gravidade da bola em queda e um ponto na barra distante do local de contato. Assim, $\alpha$ corresponde à deformação total do sistema nas proximidades do ponto de contato, resultante, predominantemente, da compressão da partícula, além das contribuições das endentações locais da bola e da barra. Portanto a deformação $\alpha$ é calculada (com o auxílio de algum método de quadratura numérica) a partir da velocidade inicial de impacto, da massa da bola e da curva de força versus tempo medida experimentalmente. A Equação (7) é válida até a chegada das ondas refletidas de deformação nas estações de medida (onde os sensores de deformação se encontram posicionados). Quando isso ocorre, torna-se necessária a deconvolução do sinal [10, 14].

As Equações (3) e (7) são válidas para o impactor com geometria esférica. No caso de o impactor apresentar forma cilíndrica, um procedimento distinto de cálculo deve ser adotado [17].

\subsection{Células de carga de impacto do LTM/COPPE}

Células de carga de impacto medindo quatro diferentes diâmetros foram projetadas e instaladas no Laboratório de Tecnologia Mineral da COPPE (Tabela 2). Esses diferentes diâmetros são necessários, uma vez que a intensidade do sinal (e a resolução do sistema) é diretamente influenciada pelo diâmetro da barra. A combinação desses diferentes diâmetros às diferentes energias de impacto, empregadas em cada uma das células de carga de impacto, permite que resultados consistentes possam ser obtidos em ensaios com partículas no intervalo de 0,3 até $100 \mathrm{~mm}$ de tamanhos. Cabe ressaltar que os valores de resolução em força, indicados na Tabela 2, representam aqueles obtidos nos equipamentos no LTM/COPPE, na condição atual de operação. Esses valores podem ser reduzidos de forma significativa, com a adoção de diferentes sistemas de aquisição de dados (o uso de osciloscópios digitais de alta resolução, por exemplo), bem como da redução das fontes de ruído eletrônico no sistema. Essa é uma área de desafio constante na operação da CCI.

A Figura 3 ilustra duas das CCI instaladas na COPPE. Os sistemas de disparo do impactor usados nas células de carga de impacto de 19, 63 e $100 \mathrm{~mm}$ de diâmetro são o eletromagnético e o de vácuo, empregado na CCI de $9 \mathrm{~mm}$. Os strain gauges utilizados são do tipo semicondutor. O sistema de aquisição de dados (baseado em placa de aquisição de dados fabricada pela National Instruments Inc.) é utilizado em freqüência de até $1 \mathrm{MHz}$.

\subsection{Propriedades das barras}

É importante determinar, com precisão, as propriedades da barra, de modo que a célula de carga de impacto possa ser usada para gerar informações quantitativas com a maior precisão e acurácia.

A densidade $(\rho)$ é determinada pesando e medindo as dimensões de bigornas dos mesmos materiais usados em

Tabela 2 - Resumo das características das células de carga de impacto instaladas na COPPE.

\begin{tabular}{c|c|c|c|c}
\hline Diâmetros $(\mathbf{m m})$ & $\mathbf{9}$ & $\mathbf{1 9}$ & $\mathbf{6 3}$ & $\mathbf{1 0 0}$ \\
\hline Impactores usados $(\mathrm{kg})$ & 0,009 a 0,065 & 0,032 a 0,67 & 0,67 a 4,6 & 3,4 a 60 \\
\hline Energia máxima de impacto utilizada $(\mathrm{J})$ & 0,065 & 0,85 & 88 & 1200 \\
\hline Tamanhos de partículas $(\mathrm{mm})$ & 0,3 a 2 & 2 a 16 & 16 a 80 & 60 a 120 \\
\hline Resolução em força $(\mathrm{N})$ & 2 & 10 & 400 & Indisponível \\
\hline
\end{tabular}


cada uma das CCI. Por exemplo, para o caso da célula de carga de impacto de 63 mm, construída em aço AISI 4340, ela é dada por $7885,5 \pm 4,2 \mathrm{~kg} / \mathrm{m}^{3}$. O valor reportado, na literatura, para esse tipo de aço, é de 7840 kg/m³ [19].

A velocidade de propagação da onda mecânica, no interior da barra $(C)$, é usada no cálculo das deformações (Equação 7), bem como da energia de fratura de partículas. Ela pode ser medida, convenientemente, a partir de um experimento no qual uma esfera de aço é solta a partir de uma altura conhecida, diretamente contra a superfície da barra, medindo-se a tensão de saída da ponte de Wheatstone $\left(V_{\text {out }}\right)$, em função do tempo. Um resultado típico desse experimento é apresentado na Figura 4 para a célula de carga de $63 \mathrm{~mm}$. A partir do tempo transcorrido desde a passagem da onda compressiva pelos strain gauges, a reflexão da onda de tração (igual a 1453,3 $\pm 0,2 \mu S$ ) é duas vezes a distância entre a posição onde se encontram os strain gauges e a extremidade inferior da barra (2x3,81 m), tem-se $C=5241,8 \pm$ $38,4 \mathrm{~m} / \mathrm{s}$

O módulo de elasticidade da barra é, diretamente, usado no cálculo das cargas (Equação 2) na CCI e, indiretamente, tanto no cálculo das deformações quanto da energia de fratura. Um dos métodos mais precisos de medida se baseia na medida da velocidade de propagação da onda de vibração através da barra. Nesse caso, ele é dado por

$Y=C^{2} \rho$

que, para o caso da barra da CCI de 63 mm, é igual a $Y=5241,8^{2}$ x 7885,5 GPA. A Tabela 3 compara esse valor ao reportado na literatura [19], bem como ao obtido pela técnica de ultrassom [20]. Ainda que superior ao obtido pelas outras técnicas, o valor do módulo de elasticidade, medido a partir da velocidade de propagação da onda, na CCI, é consistente com os demais, sendo ele adotado nos cálculos.

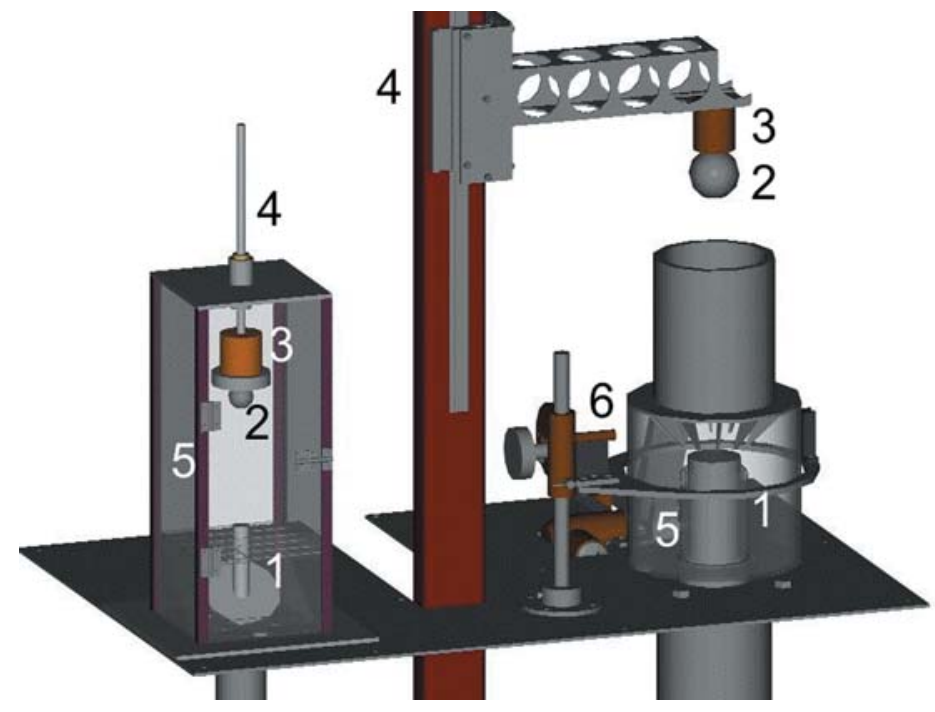

Figura 3 - Células de carga de impacto de 19 (esquerda) e $63 \mathrm{~mm}$ (direita) instaladas no LTM/COPPE (em Autocad $^{\circledR}$ ). 1: Barra da CCl; 2: impactor; 3: eletroímã; 4: dispositivo para posicionamento do impactor; 5: caixa de coleta dos fragmentos e 6: sistema de laser/foto-diodo.

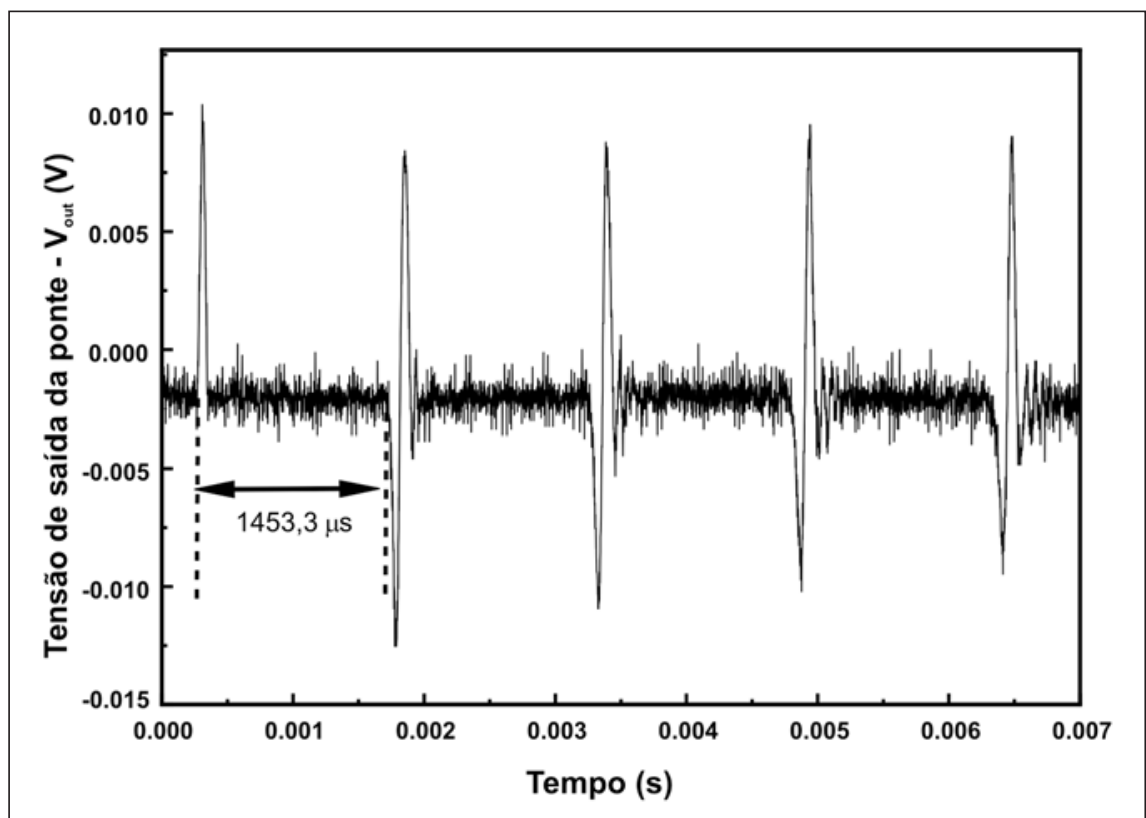

Figura 4 - Cálculo do tempo de reflexão da onda de deformação na CCI 63mm.

Tabela 3 - Valores do módulo de elasticidade para a bigorna da CCI de $63 \mathrm{~mm}$ (aço AISI 4340) - valores médios com desvio-padrão entre parênteses).

\begin{tabular}{c|c}
\hline Técnica & $\boldsymbol{Y}$ (GPa) \\
\hline Velocidade da onda de deformação na CCl & $216,7 \pm 3,2$ \\
\hline Ultrassom [20] & $212,9 \pm 1,2$ \\
\hline Dado da literatura [19] & 207 \\
\hline
\end{tabular}




\section{Calibração da célula de carga de impacto}

Como resultado da alteração da resistência dos strain gauges, na barra da CCI, durante a sua adesão, da influência das resistências introduzidas no sistema pelos fios de conexão e da temperatura de operação, o parâmetro $\lambda$ da Equação 3, necessário para o cálculo das forças, precisa de ser determinado por calibração. Esta é realizada pela comparação de resultados experimentais aos de um modelo teórico, baseado na teoria de contatos de Hertz [18] e da propagação de ondas elásticas em sólidos (Equação 7). A teoria de contatos elásticos de Hertz permite calcular a força de contato resultante da colisão de uma esfera com raio $R$ contra uma superfície plana (no caso, a superfície da barra), dada por

$F_{\text {Hertz }}=\frac{4}{3} \frac{k_{r} k_{b}}{k_{r}+k_{b}} R^{1 / 2} \alpha^{3 / 2}$

na qual $R$ é o raio da esfera, e $k_{r}$ e $k_{b}$ são a rigidez da barra e da bola, respectivamente, dadas por Y / $\left(1-\mu^{2}\right)$, em que $\mu$ é a razão de Poisson.

O experimento de calibração consiste em armazenar o sinal resultante do impacto de uma esfera de aço, de massa e rigidez conhecidas, diretamente contra a barra da CCI, a partir de uma determinada altura. Esse ensaio é idêntico àquele usado no cálculo da velocidade de propagação de onda na barra, conforme descrito anteriormente. A partir das tensões de saída medidas do circuito ponte $\left(V_{\text {out }}\right)$ em função do tempo, do módulo de elasticidade, da área da barra e do fator de gauge, a Equação (3) permite fazer o cálculo de valores do produto $F \lambda$, em função do tempo. Por outro lado, a combinação das Equações (7) e (9), em um procedimento recursivo de integração numérica, permite fazer o cálculo da curva de força teórica versus tempo, conforme é ilustrado na Figura 5. Lançando-se em gráfico os valores máximos de $F \lambda$ medidos e da força teórica, para ensaios realizados com diferentes velocidades de impacto e massa do impactor, obtém-se a constante $\lambda$ pela declividade (Figura
6), que, para a CCI de $9 \mathrm{~mm}$, é igual a 0,50. A divergência observada entre resultados medidos e calculados se deve à deformações plásticas incipientes. No caso da CCI de $63 \mathrm{~mm}$, o valor de $\lambda$ encontrado é igual a 0,35. De qualquer maneira, esses valores devem ser, periodicamente, verificados, tendo em vista o efeito significativo da temperatura na resistência dos strain gauges do tipo semicondutor.
Comparações entre resultados experimentais considerando-se o valor de $\lambda$ corrigido e resultados teóricos para o caso da queda de uma esfera de aço alto cromo (com $Y_{b}=203,5$ GPa e $\mu=0,29$, obtidos a partir de informações do fabricante) são apresentadas nas Figura 7 e 8, para as células de carga de 9 e $63 \mathrm{~mm}$, respectivamente. Observa-se que a correspondência é excelente em ambos os casos, o que demonstra que a CCI ofere-

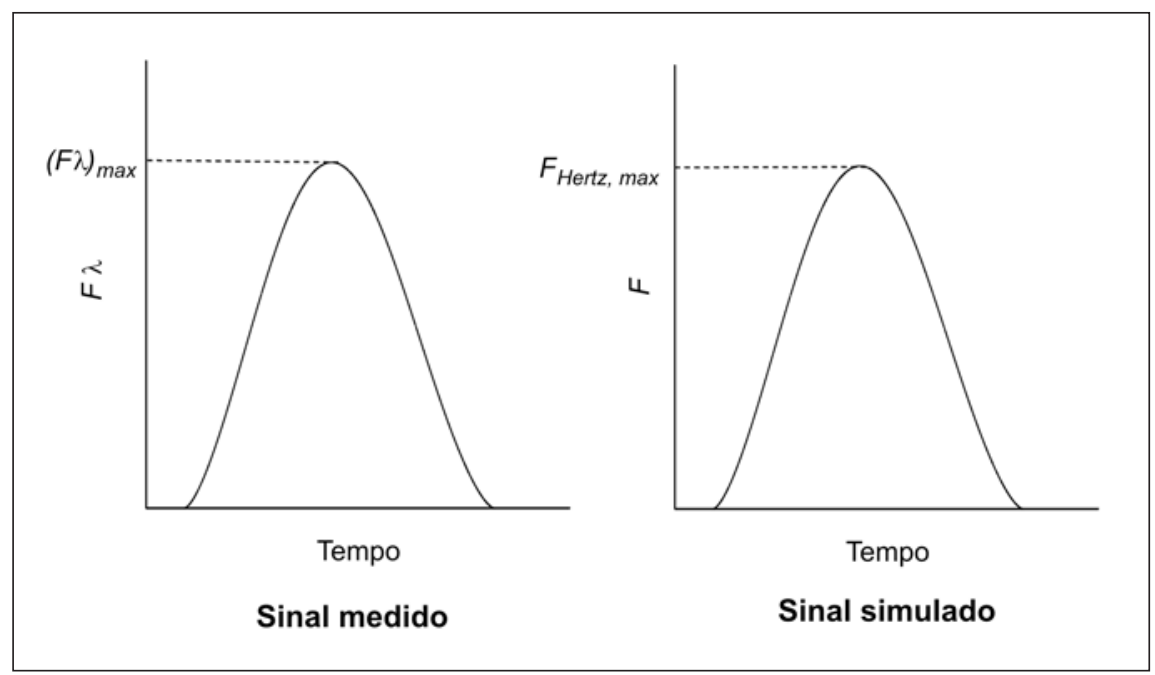

Figura 5 - Figura esquemática que compara a curva de força-tempo calculada a partir da teoria de Hertz e da força-lambda medida em função do tempo.

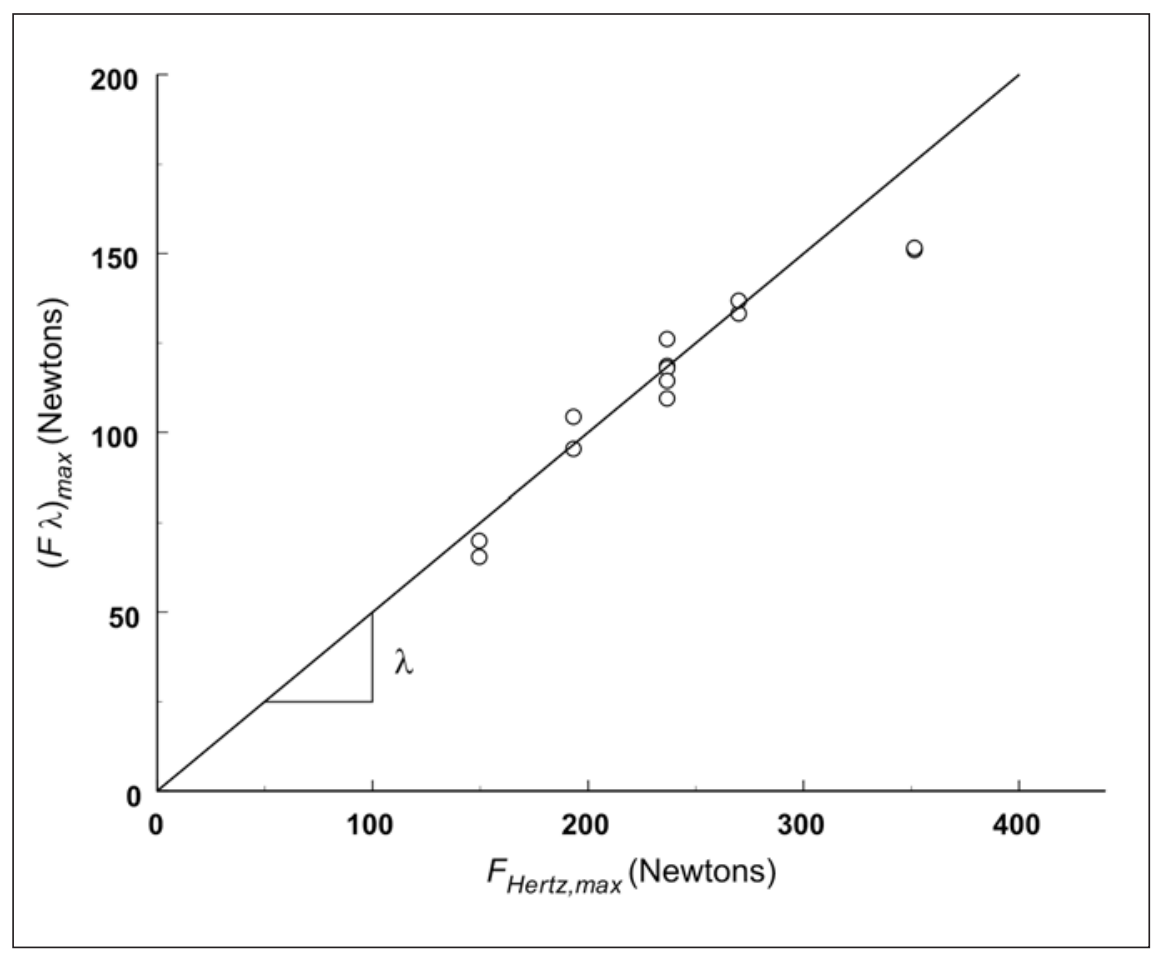

Figura 6 - Cálculo do fator de correção da força $(\lambda)$ para a $\mathrm{CCl}$ de $9 \mathrm{~mm}$. 
ce uma representação precisa da força exercida na face superior da barra, bem como que condições de queda livre prevalecem no movimento da esfera em queda.

A aplicação do aparelho na fratura de partículas é analisada na segunda parte desse artigo.

\section{Conclusões}

A caracterização de materiais, para a cominuição, a partir de ensaios de fragmentação de partículas individuais, hoje, já atingiu a popularidade dos métodos tradicionais de moabilidade e britabilidade usados há mais de meio século. Entre os diferentes equipamentos de ensaios, a célula de carga de impacto ocupa uma posição de destaque, pois, além de permitir avaliar a relação entre a energia de impacto e a fragmentação resultante (como faz o pêndulo duplo e o drop weight tester), ela, ainda, permite a medida precisa da resistência e da energia específica de fratura primária de partículas individuais.

Ensaios de calibração demonstraram a elevada acurácia da barra, tendo em vista a excelente correspondência entre o resultado do ensaio e o teórico obtido a partir da teoria de Hertz. Além disso, o módulo de elasticidade, calculado a partir da medida da velocidade de propagação da onda elástica, se mostrou comparável aos resultados obtidos com a técnica de ultrassom, que demonstra a validade do procedimento adotado.

As facilidades atualmente disponíveis no LTM/COPPE, que contam com células de carga de impacto com diâmetros de 9 a $100 \mathrm{~mm}$, fazem com que esse seja o centro melhor em nível internacional, para o estudo de fragmentação de partículas por impacto.

\section{Agradecimentos}

Os autores agradecem à FUJB, FAPERJ e ao CNPq, pelo auxílio financeiro para a construção das células de carga de impacto. Os autores aproveitam para reconhecer a importante contri-

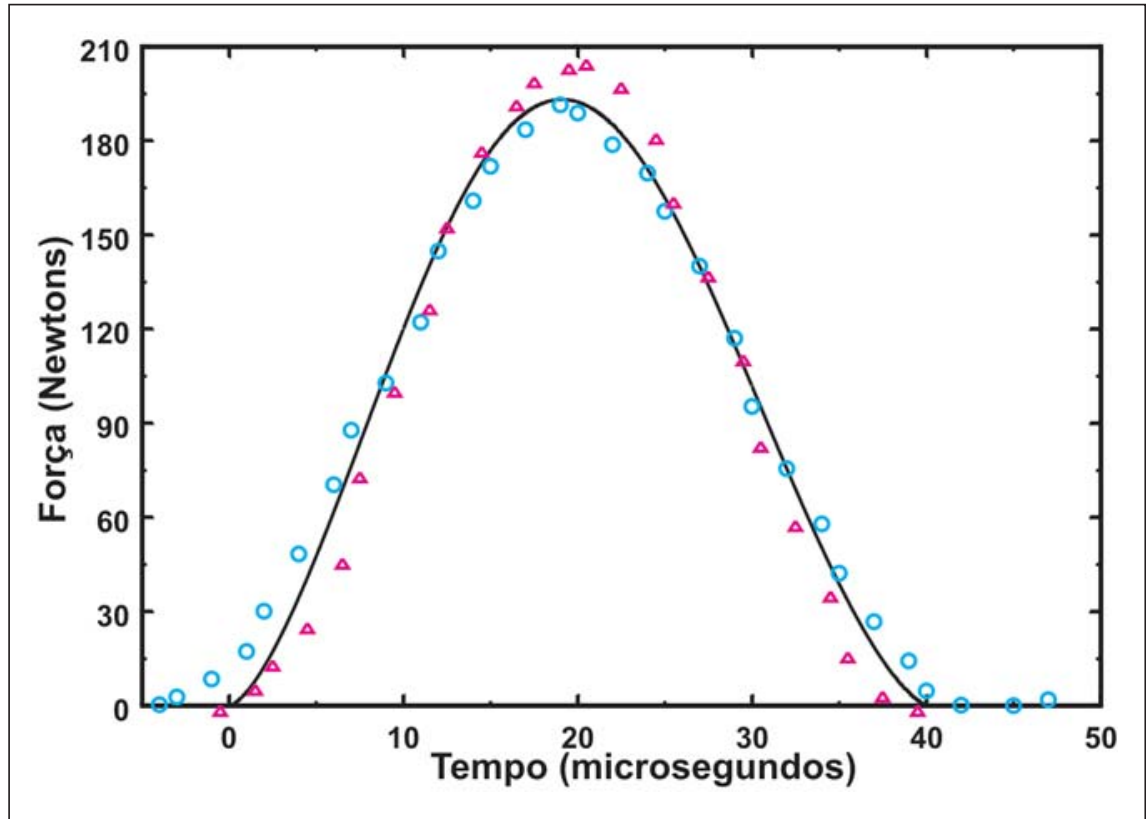

Figura 7 - Comparação entre os resultados medidos e calculados para o impacto de uma esfera de aço de $4 \mathrm{~g}$ (9,9 mm diâmetro), a partir de uma altura de 1,7 cm (linha sólida: teoria; símbolos: experimentos replicados), na CCl de $9 \mathrm{~mm}$.

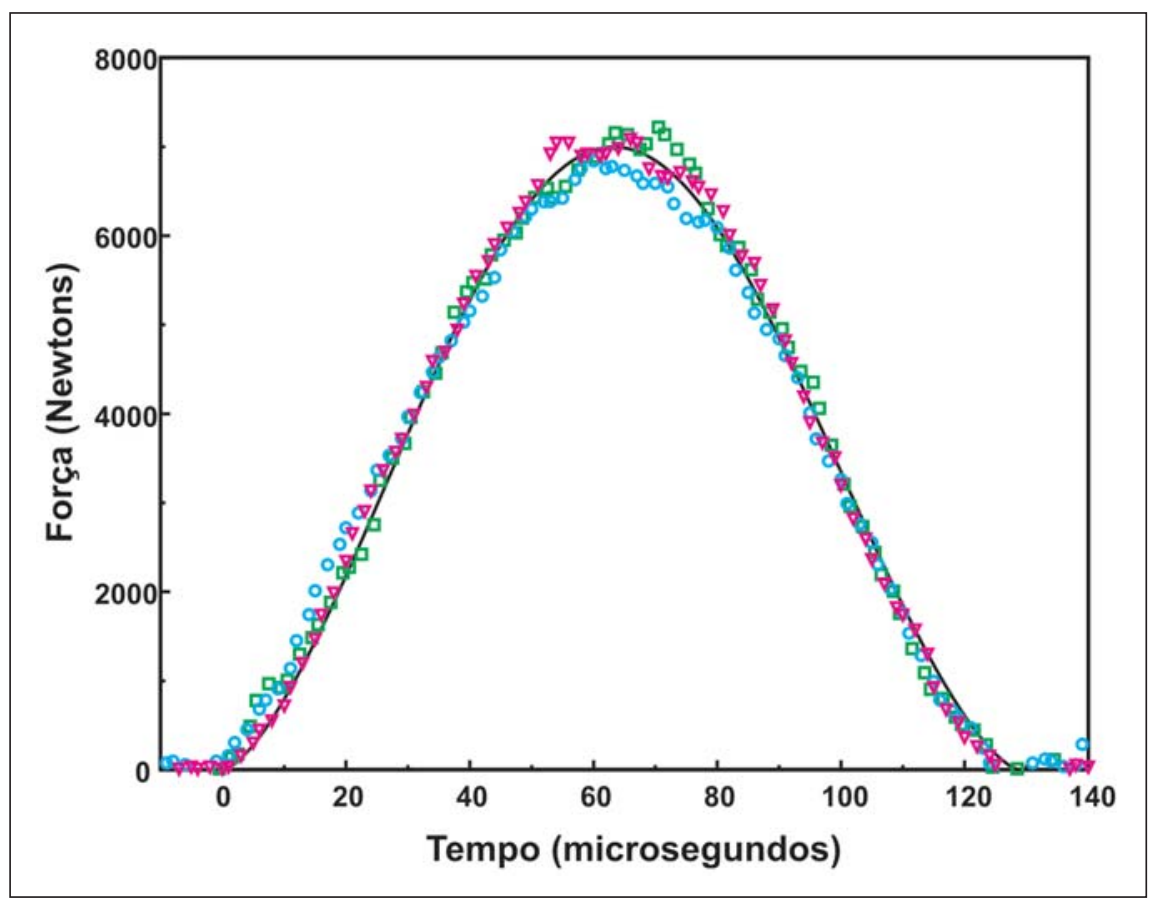

Figura 8 - Comparação entre os resultados medidos e calculados para o impacto de uma esfera de aço de $230 \mathrm{~g}$ (38,9 mm de diâmetro), a partir de uma altura de 6,2 cm (linha sólida: teoria; símbolos: experimentos replicados), na $\mathrm{CCl}$ de $63 \mathrm{~mm}$.

buição dos engenheiros Vitor Mainenti L. Lopes, Vinícius Figueiredo Pereira e Carlos Magno Vasquez (ex-bolsistas de iniciação científica do CNPq no LTM), pela valiosa contribuição no projeto e construção das CCI.

\section{Referências bibliográficas}

1. BOND, F.C. Crushing and grinding calculations. British Chemical Engineering, v. 6, p. 378-391, 543-548, 1960. 
Luís Marcelo M. Tavares et al.

2. BEARMAN, R. A., PINE, R.J., WILLS, B.A. The use of fracture toughness testing in characterizing the comminution potential of rock. In: MMIJ/IMM Joint Symposium, 1989. Anais... Kyoto. p.161-180.

3. CLEAVER, J.A.S., GHADIRI, M., ROLFE, N. Impact attrition of sodium carbonate monohydrate crystals. Powder Technology, v. 76, p. 15-22, 1993.

4. UNLAND, G., SZCZELINA, P. Coarse crushing of brittle rocks by compression. International Journal of Mineral Processing, v. 74S, p. S209-S217, 2004.

5. PRASHER, C.L. Crushing and grinding process handbook. John Wiley \& Sons, 1987. 464p.

6. TAVARES, L.M., KING, R.P. Singleparticle fracture under impact loading. International Journal of Mineral Processing, v. 54, p. 1-28, 1998.

7. WEICHERT, R., HERBST, J.A. An ultra fast load cell for measuring particle breakage. In: World Congress Particle Technology, 1986. Nurnberg. Anais... Part II, p. 3-15.

8. KING, R.P., BOURGEOIS, F.S. Measurement of fracture energy during single-particle fracture. Minerals Engineering, v. 6, p. 353-368, 1993.
9. HÖFFLER, A. Fundamental breakage studies of mineral particles with an ultrafast load cell device. Salt Lake City: University of Utah, 1990. (Tese de Doutorado).

10. TAVARES, L.M. Energy absorbed in breakage of single particles in drop weight testing. Minerals Engineering, v. 12, p.43-50.

11. NAPIER-MUNN, T.J., MORRELL, S., MORRISON, R.D., KOJOVIC, T. Mineral comminution circuits: their operation and optimization. JKMRC Monograph Series, University of Queensland, 1996.

12. FRANDRICH, R.G., CLOUT, J.M.F., BOURGEOIS, F.S. The CSIRO Hopkinson bar facility for large diameter particle breakage. Minerals Engineering, v. 9, p. 861-869, 1998.

13. BRIGGS, A. A fundamental model for cone crusher. JKMRC, University of Queensland, Brisbane, 1997. (Tese de Doutorado).

14. BOURGEOIS, F.S., BANINI, G.A. A portable load cell for in-situ ore impact breakage testing. International Journal of Mineral Processing, v. 65, p. 31-54, 2002.

15. LOPES, V.M.L. Projeto, construção $\boldsymbol{e}$ calibração de célula de carga de impacto para estudos de fragmentação de materiais particulados. Projeto de Formatura em Engenharia Mecânica, Escola Politécnica, UFRJ, 2002. 34p.

16. PEREIRA, V.F. Projeto e construção de equipamento para ensaios de fragmentação de materiais particulados de até $120 \mathrm{~mm}$ por impacto. Projeto de Formatura em Engenharia Mecânica, Escola Politécnica, UFRJ, 2004. 85p.

17. TAVARES, L.M., KING, R.P. Measurement of the load-deformation response from impact-breakage of particles. International Journal of Mineral Processing, v. 74S, p. S267S277, 2004.

18. GOLDSMITH, W. Impact: the theory and physical behaviour of colliding solids. London: Dover, 1960, 379p.

19. ROSS, R.B. Metallic materials specification handbook. Chapman \& Hall, 1980. p. 527.

20. LIMA, A. Calibração da célula de carga de impacto e aplicação na fratura de materiais particulados. Projeto de Formatura em Engenharia Metalúrgica, Escola Politécnica, UFRJ, 2005. 47p.

Artigo recebido em 30/09/2005 e aprovado em 30/12/2005.

\title{
REM - Revista Escola de Minas 70 anos divulgando CIÊNCIA.
}

\author{
****** \\ REM: a mais antiga revista técnico- \\ científica do setor mínero-metalúrgico.
}

$\star * * * * *$

www.rem.com.br

$* * * * * *$ 